

\title{
The Final Frontier
}

\section{A medical student's mission to boldly dream where no dream has gone before}

Laura Drudi*

One simple idea can be the spark of a dream that begins to shape a lifelong journey of exploration, discovery, and transformation. I recall tilting my head towards the night sky at the age of nine years old. I was drawn to the vastness and beauty of space and I further envied those who could ride rickets to their destination. As I stared in complete admiration at the night sky, I hoped a space tourist. My dreams were fostered as if it were more of a destiny than a mere fantasy I knew I wasn't content with being bound to the Earth and my imagination, mind and heart began to soar to the limitless possibilities that the void of space encompassed. That void harbored a sense of awe adventure and a belief that anything is possible. This dream was hamessed into a passion that drove my motivation and led me to excel. I decided to pursue an unconventional career path pursuing space medicine. However, my passion was unquestionable allowing me to overcome challenges paving the way to success. I cannot encapsulate the breadh of growth I have undergone University. I have thaved the word to unique dreams agains all fears of fallere. I have worked in affiliation with renowned internation institutions, and further presented at national and international conferences. Befor I knew it I began transforming into a medical student leader for the aerospace industry. I began receiving support and encouragement from a variety of agencies that

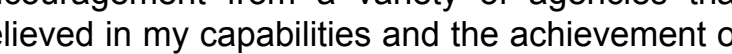
my goals. I was selected by the Canadian Space Agency and NASA to be the sole Canadian student to attend the NASA Ames Research Center on a research grant - the ultimate dream realized for an avid space enthusiast. I went on to being recognized for my leadership in the aerospace medica program, the Canadian Medical Association, Space Medicine Association, and became a Quebec finalist in the 2011 Rhodes Scholarship selection. Through all these experiences, I have grown as a medical student and developed skills essential in international and interdisciplinary collaboration, leadership, and aptitudes required to attain my goals. However, it wasn't these successes that defined my ability to rise to the challenge, but the failures that $I$ encountered along the way. am a dreamer, innovator and attainer. I dream of possibilities, I create opportunities and I realize my goals through various avenues.

pace is a magical place and humanity has always been pulled towards its enchantment. from gods in the blackness of space to the latersientists who searched for universal truth and siscovists the movement of planets and established the aws of physics. It is human nature to be thinkers and explorers, and space opened the human imagination because it was unknown and remains unknown to this day. Humanity's curiosity, quest for knowledge and greed led to a rich history of space exploration that set the standards for success in the space industry worldwide. And space continues to blaze new paths at the forefront of human 
understanding. My goal is to be at that frontier and begin an expedition unparalleled by any other.

To this very day, I tilt my head towards the night sky. I don't know if I will ever have the chance to become one of the select few to travel beyond Earth's gravity, but one thing I can guarantee is that I am going to make the attempt. As the frontiers do the ideas, creativily and innovation of talented people. There is no boundary to space and there is no limitation to the imagination. The final frontier

isn't space; I believe it's the breath of the human magination. With that in mind, this expedition that have embarked on is bound to be an exciting one. is with great pleasure the McGill Journal of Medicine Issue 13.2 will have aerospace medicine as the focus section. I hoped to share my passions or space and medicine with the community at arge, and I am privileged and humbled to have participation and support from the space life sciences community.

Thank you

Laura Drudi (M.D., C.M. candidate 2013) is a third year medical student at McGill University. Her interest in combining her two passions of space and medicine has led her to conduct aerospace medicine research. She will be taking a one year's leave of absence from the Faculty of Medicine and will be pursuing a Diploma of Space Studies and an MSc

in Experimental Surgery prior to completing her MDCM degree. She hopes to work for the manned space program as a flight surgeon and to further continue her research in space life sciences.
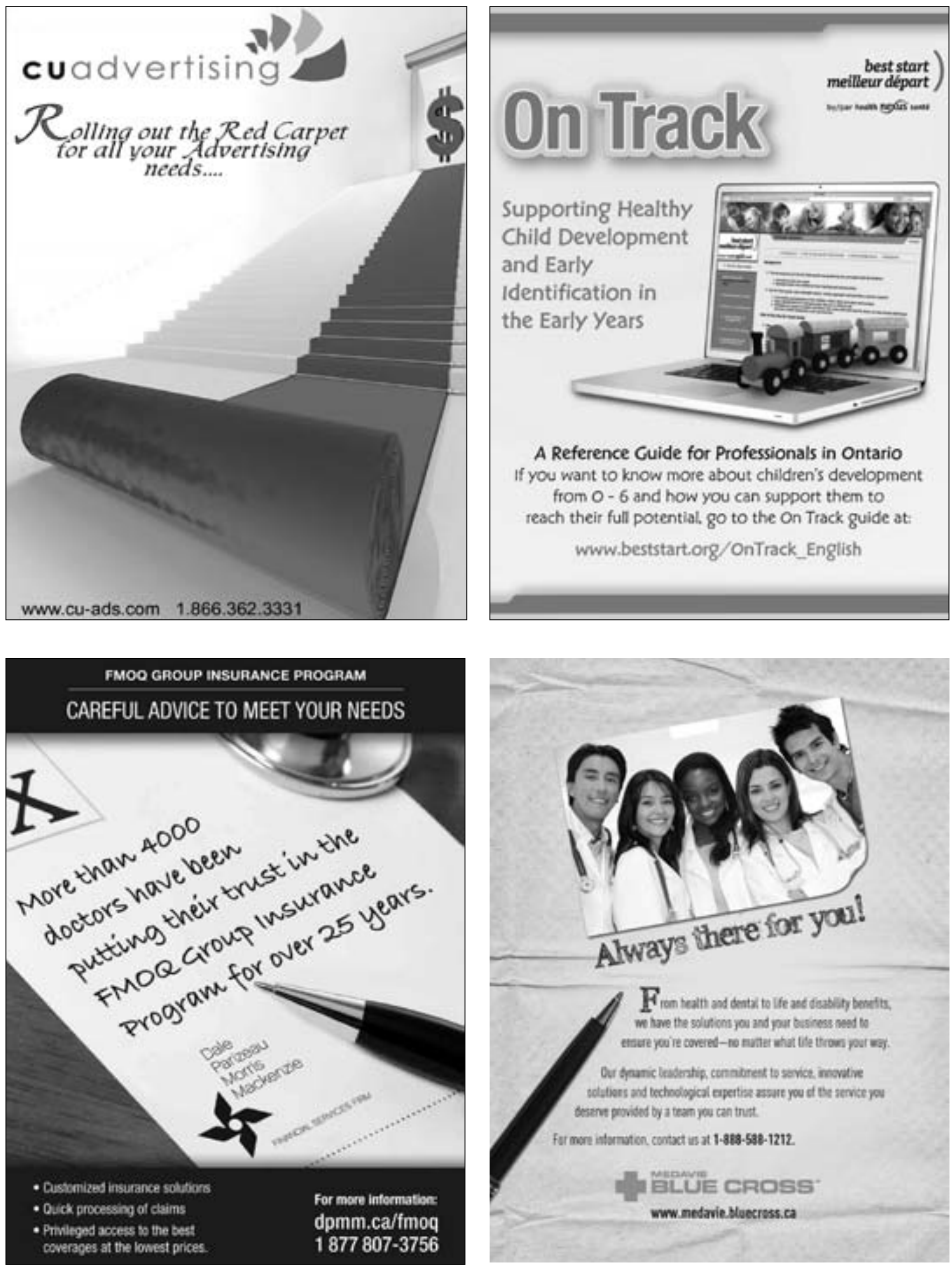